\title{
A COMPLEXIDADE EM PESQUISAS EM LINGUÍSTICA APLICADA QUE ABORDAM A PRÁTICA ESCRITA NA FORMAÇÃO DE PROFESSORES
}

\author{
Maria Eugenia Witzler D’ESPOSITO \\ GPeAHF/CNPq \\ eugeniadesposito@yahoo.com.br \\ Gisele de OLIVEIRA \\ FEFISO/ACM Sorocaba, GPeAHF/CNPq \\ gidez2001@ig.com.br
}

\begin{abstract}
Resumo: $O$ intuito deste artigo é compartilhar as experiências de duas professoras pesquisadoras que desenvolvem pesquisas na área de linguística aplicada, sob a perspectiva da complexidade (MORIN, [1990] 2006a,b, [1990] 2008, [2005] 2006, [2008] 2010; MORAES, 2006, entre outros ) e abordam a prática escrita na formação de professores. D'Esposito (2012) pesquisa o desenho e a implementação de um curso a distância de prática escrita em língua inglesa, sob a perspectiva da complexidade, para professores do ensino médio da rede pública estadual de São Paulo. Oliveira (2012) investiga a disciplina presencial de ensino de língua materna direcionada à produção textual em um curso de licenciatura em Educação Física, observando o curso e a formação dos professores pelo viés da complexidade. Iniciamos o artigo abordando a perspectiva da complexidade, passamos, então, à apresentação das experiências de docência vividas e concluímos apresentando reflexões acerca das pesquisas.
\end{abstract}

Palavras-chave: Complexidade. Linguística aplicada. Formação de professores. Prática escrita.

\begin{abstract}
This paper aims at sharing the experience of two teacher researchers who develop their studies in the applied linguistics area, in view of the complexity theory (MORIN, [1990]2006a,b, [1990]2008, [2005]2006, [2008]2010; MORAES, 2006, among others), and work with writing practice in teachers' formation. D'Esposito (2012) researches the design and implementation of an online writing course of English, under the complexity perspective, for regular high schools teachers in São Paulo. Oliveira (2012) investigates a face to face subject on the teaching of the mother tongue with focus on written production in an undergraduate course of Physical Education. We start the article by presenting complexity, and then we move on to the presentation of the teaching practices experienced and we conclude by sharing some reflections on the researches.
\end{abstract}

Keywords: Complexity. Applied linguistics. Teachers' formation. Writing practice. 
A comunicação escrita sempre foi uma necessidade pessoal, profissional e acadêmica, embora muitas pessoas a considerassem uma habilidade não tão importante quanto a comunicação oral. Todavia, com a incorporação de novas tecnologias ao nosso quotidiano que requerem a escrita para a comunicação, a população, de forma geral, passa a enxergar essa prática, novamente, como uma habilidade necessária. Ser capaz de expressar-se e se fazer entender, não apenas oralmente, mas também por meio da escrita, em vários contextos e com objetivos diversos, torna-se uma preocupação. Assim, as pessoas se conscientizam que aprender a produzir textos, bem como refletir a respeito de suas produções, seja um aspecto relevante para sua formação e uma exigência do mundo contemporâneo.

Tendo como base esse contexto, este artigo tem por objetivo compartilhar as experiências de duas professoras pesquisadoras que trabalham com prática escrita na formação de docentes, e que são fruto de suas pesquisas de doutoramento. D’Esposito (2012) investiga o desenho e a implementação de um curso a distância de prática escrita em língua inglesa, sob a perspectiva da complexidade, para professores que atuam no ensino médio da rede pública estadual de São Paulo. Por sua vez, Oliveira (2012) que tem como contexto de sua pesquisa uma disciplina presencial de ensino de língua materna direcionada à produção textual em um curso de licenciatura em Educação Física, observa e reflete sobre o curso e a formação dos professores pelo viés da complexidade. Dessa forma, este artigo apresenta pesquisas na área da linguística aplicada que abordam a complexidade de formas diversas e que trabalham com a prática escrita em língua materna na formação pré-serviço e em língua estrangeira na formação de docentes em serviço.

Em relação à prática escrita, as professoras pesquisadoras a enxergam como um processo de construção/desconstrução/reconstrução e de autonegociação de significados (ZAMEL, 1987) sendo este, portanto, o enfoque dado por elas à produção textual.

Com o intuito de compartilhar tais experiências, este artigo está organizado em três partes. Iniciamos abordando a mudança paradigmática que 
ocorreu na educação nos últimos tempos, apresentando a complexidade. Passamos, então, à apresentação das experiências de docência das professoras pesquisadoras. Concluímos apresentando reflexões acerca das contribuições da perspectiva da complexidade para o desenvolvimento das pesquisas na linguística aplicada e no trabalho desenvolvido com os professores em formação.

\section{Do simplificador ao complexo}

As crenças, valores e técnicas compartilhadas por uma comunidade (KUHN, [1962] 2009, p. 225) ou os "princípios ocultos que governam nossa visão das coisas e do mundo sem que tenhamos consciência disso" (MORIN, [2005] 2006, p.10) são os paradigmas que nos cercam. Eles, portanto, se alteram ao longo do tempo, uma vez que valores, crenças, conceitos e ideias estão em contínuo processo de (re)construção (ASSMANN, 1998). Essas mudanças se dão, também, em relação à educação, modificando a forma como a sociedade enxerga a escola e os docentes sua prática e a formação que oferecem. Assim, na contemporaneidade buscamos romper com o paradigma educacional tradicional que é racionalista; vê o aluno como um espectador e o professor como quem detém o saber e o transmite; preocupa-se com 0 resultado e não o processo; apresenta currículos lineares nos quais as disciplinas não se articulam; releva o diálogo e as interações; divide, desvincula e individualiza (BEHRENS e OLIARI, 2007, p. 59-61; MORAES, 2006, p. 43), desconsiderando a subjetividade (MORIN, [1990] 2008) e o caráter das experiências.

Conscientes de que este paradigma não atende mais nossas necessidades, procuramos uma nova forma de olhar a educação, que recupere e traga novamente os sujeitos e suas subjetividades para o processo do ensino-aprendizagem, buscando um saber integrador, que nos permita estabelecer relações e fazer conexões (MORIN, [2005] 2006, p.7; [1999] 2006a, p. 11). Este novo olhar é caracterizado pelo paradigma emergente ou complexo, que objetiva articular, integrar e associar modos diversos de pensar, 
tecendo relações entre o sujeito e os objetos, acontecimentos, ações e interações (MORIN [2005] 2006, p. 63-105; MORAES, 2006, p. 71-73; BEHRENS e OLIARI, 2007, p. 63; MARIOTTI, 2007, p.139), pois como afirma Morin ([1999] 2006a, p. 89; [2008] 2010, p. 190) a palavra complexo advém do termo complexus que significa "o que é tecido junto".

Sob essa perspectiva o conhecimento é percebido e coproduzido por meio do nosso diálogo com o mundo (MORIN, [1990] 2008, p. 204-205, MORAES, 2006, p. 88) considerando não só o uso da nossa razão, mas também das nossas sensações, emoções, sentimentos e intuições. O conhecimento é um processo que não se constitui por verdades fixas, mas mutáveis e "só é conhecimento enquanto organização, relacionado com as informações e inserido no contexto delas" (MORIN, [2005] 2006, p. 16). Como salienta Morin ([2008] 2010, p. 190),

O conhecimento complexo procura situar seu objeto na rede à qual ele se encontra conectado. (...) O conhecimento complexo objetiva reconhecer o que liga ou religa o objeto a seu contexto, processo ou organização em que ele se inscreve. Na verdade, um conhecimento é mais rico, mais pertinente a partir do momento em que o religamos a um fato, um elemento, uma informação, um dado, de seu contexto.

Nesse processo tudo está interligado, entrelaçado e esta interconexão permite que enriquecimentos não lineares ou previamente determinados sejam criados por meio da exploração das conexões, relações, integrações e pela própria vivência do processo.

Morin ([1999] 2006a, p. 95-96; [2005] 2006, p. 74-77) propõe três princípios que nos ajudam a compreender o pensamento complexo: 0 hologramático, o recursivo e o dialógico. O princípio hologramático está associado à metáfora do holograma e estabelece a relação entre todo e parte(s), uma vez que a(s) parte(s) está no todo, como o todo está na(s) parte(s), havendo um enriquecer das partes pelo todo e o todo pelas partes por meio desta relação. O princípio do circuito recursivo refere-se ao fato de que produtos e efeitos são, eles próprios, produtores e causadores daquilo que os produz. O princípio dialógico concebe a possibilidade de se estabelecer um diálogo entre elementos que inicialmente parecem ter uma relação antagônica, 
mas que podem ser complementares e indissociáveis, permitindo, assim que mantenhamos a dualidade e assumamos racionalmente a inseparabilidade de noções contraditórias.

Esses princípios possibilitam a compreensão da complexidade e um novo olhar para nossa prática docente para que possamos compreendê-la e possibilitar oportunidades de aprendizagem aos alunos.

\section{Trabalhando a prática escrita pelo viés da complexidade}

Abordamos nesta seção o relato das experiências vividas pelas professoras pesquisadoras que trabalham sob a perspectiva da complexidade, apresentando a seguir os contextos de suas pesquisas e o trabalho desenvolvido.

\subsection{Prática escrita em língua estrangeira}

A proposta de D'Esposito (2012) relaciona-se ao desenho e à implementação de um curso a distância de prática escrita em língua inglesa para professores de língua inglesa do ensino médio da rede pública estadual de São Paulo, sob a perspectiva da complexidade (MORIN, [2005] 2006; [1999] 2006a). O curso partiu da identificação das necessidades manifestadas por professores que atuam nesse contexto e daquelas expressas na Proposta Curricular do Estado de São Paulo para a disciplina de Língua Estrangeira Moderna (São Paulo, 2008) e nos Cadernos redigidos pela Secretaria da Educação do Estado de São Paulo (São Paulo, 2008 a-g) e objetivava que os professores participantes aprendessem a escrever em língua inglesa, escrevendo e refletindo sobre o processo de elaboração de textos, além de refletirem sobre a experiência vivida e como ela repercutia em suas práticas docentes ao ensinarem a escrever em língua inglesa.

Como afirma a autora (D'ESPOSITO, 2012, p. 75-76), o intuito era promover um curso complexo de prática escrita que estabelecesse uma 
relação hologramática e recursiva entre o conteúdo do curso, a prática docente dos participantes, a escola e a sociedade; possibilitasse que a professora pesquisadora e os professores participantes (reservados os papéis desempenhados) enfrentassem e trabalhassem com os desafios, incertezas, riscos, o imprevisível e o indeterminável; incluísse o observador na observação; considerasse o contexto e a cultura; não buscando um saber total, mas, sim, um conhecimento pertinente e coconstruído por meio de um trabalho colaborativo.

O ambiente a distância e a utilização de uma plataforma permitiram contar com um espaço de aprendizagem adequado para o processo de produção escrita, de negociação e autonegociação de significados, no qual as informações, as reflexões e os registros puderam ser disponibilizados e as atividades desenvolvidas, além de acesso a sites (que auxiliassem em relação a aspectos gramaticais) e dicionários online.

D'Esposito (2012) apresenta uma situação de aprendizagem real, ou seja, uma situação que faz ou faria parte do quotidiano dos professores participantes, que foi experienciada por meio das tarefas propostas. Tais tarefas solicitavam, por exemplo, pesquisa e produção individual e coletiva e, para o seu desenvolvimento, os professores participantes contaram com materiais de suporte explanatórios e exploratórios elaborados pela professora pesquisadora. Esses materiais foram disponibilizados e trabalhados ao longo do curso e abordavam aspectos tais como: planejamento, confecção de rascunho, revisão e editoração; o que envolve o processo da escrita; tom e estilo, e a construção de frases e parágrafos, dentre outros. O curso propiciava um diálogo entre a parte teórica e a prática, além de uma integração e relevância entre o curso de prática escrita em língua estrangeira e as vidas pessoais ou profissionais e o mundo, uma vez que as produções escritas abordadas fazem parte da prática docente dos professores participantes, pois são os textos que trabalham com seus alunos em sala de aula.

A situação de aprendizagem real permeou o curso que não foi organizado e apresentado por semanas, mas por momentos, pois como afirma D'Esposito (2012, p. 130) no trecho a seguir, 
Esta foi uma tentativa de romper com a ideia de temporalidade marcada, divisão cronológica das semanas e linearidade, uma vez que a duração de cada momento variaria de acordo com a necessidade de tempo para 0 desenvolvimento daquela fase. Cada momento corresponderia a uma etapa do processo de desenvolvimento do curso, a uma parte da situação real de aprendizagem, contribuindo diretamente para o alcance dos objetivos, estando inter-relacionado aos momentos anteriores e posteriores.

Os momentos que compunham o curso dependiam, por exemplo, das interações, das necessidades, da dialogia, da recursividade, da autonomia e das reflexões que os perpassavam para o seu desenvolvimento e consequentemente o do curso (D'ESPOSITO, 2012, p. 81). Assim, este foi um curso a distância de prática escrita coconstruído pelos professores participantes e pela professora pesquisadora durante o desenvolvimento do mesmo, por meio das atividades propostas, tendo por base o pensamento complexo e os princípios propostos por Morin ([1999] 2006b, [2005] 2006p. 6370; [1990] 2008,p. 196-273), pois como ressalta D’Esposito (2012, p. 124),

em uma visão complexa, o desenho de um curso nunca é feito a priori, na integra, sendo, portanto, construído, também, ao longo de sua implementação, explorando-se as conexões, as relações, as integrações, à medida que se vivencia o processo. Assim, para mim, o termo desenho, no contexto desta pesquisa, compreende o que mais comumente se denomina desenho e redesenho.

D'Esposito (2012), baseada em Zamel (1987), entende e trabalha a prática escrita ao longo do curso como um processo de significação, reconhecendo-se a importância da geração, formulação e refinamento das ideias, considerando fatores como propósito, a existência de um leitor e comprometimento além da própria dinâmica da produção textual. $\mathrm{O}$ ato da escrita - de registro da ideia em desenvolvimento - é entendido como um processo de autonegociação e de descoberta de significado(s), que envolve a descoberta e a aproximação do que o indivíduo gostaria de expressar (ZAMEL, 1987, p. 268-269). Dessa forma, ela se desenvolve em um contínuo que possibilita uma maior reflexão sobre o pensamento (COX, 1994, p. 169-170 e FRIEDLANDER, 1996, p. 110), o processo, os aspectos estruturais, o conteúdo 
e os valores expressos, requerendo: (1) levantamento de ideias (2) elaboração de atividades e habilidades que respaldem o texto; (3) trabalho com materiais que contenham o conteúdo; (4) confecção de resumos que auxiliem na organização e controle das informações; (5) conscientização sobre o uso da língua, e (6) editoração (GRABE e KAPLAN, 1996, p. 320-327). Ademais, a escrita não é entendida como uma habilidade descontextualizada (MAYBIN, 1996) mas, sim, como uma prática de sala de aula relacionada ao mundo real, como um objeto social e não apenas escolar (PASSARELLI, 2004, p. 35-42).

Assim, como podemos notar, na pesquisa de D’Esposito (2012) a complexidade é a base do desenho e implementação do curso a distância de prática escrita em língua inglesa para professores do ensino médio da rede pública, bem como a forma pela qual a pesquisadora enxerga e trabalha a escrita.

\subsection{Prática escrita em língua materna}

Ao trabalhar com a prática escrita em língua materna na licenciatura em Educação Física, Oliveira (2012) inicia suas considerações pelo fato de não podermos isolar o estudo das necessidades, dificuldades e possibilidades dos professores em formação apenas ao Ensino Superior, uma vez que esse isolamento nos remeteria ao paradigma tradicional e não às conexões propostas pela complexidade. Além disso, como ressalta a autora, é importante destacar as experiências prévias dos alunos, pois antes mesmo de frequentarem a escola faziam uso da língua portuguesa e há tempo têm um contato com a língua no âmbito escolar.

Resultados de testes, estudos e pesquisas (PAVANELLO, 1995; GRAEFF e ONHATTE, 2006; FIORIN, 2007, entre outros) identificam dificuldades e necessidades referentes ao uso da língua materna. Isso pode demonstrar a necessidade de (re)pensarmos o ensino da língua materna. Cintra (1996, p. 18), em especial, afirma que devemos considerar a "competência inata" do falante ao considerarmos o ensino de Português para nativos. A autora destaca, ao se referir a uma proposta de Português Instrumental, a análise de 
necessidades e a definição do que é conhecido ou não pelos alunos, o que auxiliaria o planejamento. Ao nos familiarizarmos com as habilidades dos alunos e seus conhecimentos prévios, podemos planejar aulas que ofereçam oportunidades de construção e reconstrução de conhecimentos além de possibilitar aos alunos buscarem e estabelecerem novas conexões em relação ao uso da língua, que, por sua vez, podem remeter a contextos acadêmicos, profissionais ou pessoais, de acordo com as necessidades e objetivos propostos.

Antunes (2003) analisa a realidade envolvendo o ensino da leitura e escrita nos Ensinos Fundamental e Médio e apresenta problemas que se refletem no uso e na visão dos alunos acerca do ensino da língua materna na escola. No que se refere especificamente à escrita, algumas das constatações de Antunes (2003) versam sobre o fato de que: a escrita é entendida como um processo sem planejamento e sem revisão; os exercícios solicitados pedem a elaboração de listas e frases soltas; e, a prática fica centrada em habilidades motoras e de memorização das regras ortográficas.

Ao articular essas constatações à afirmação de Morin ([2008]2010) sobre o conhecimento complexo, Oliveira (2012) destaca que alguns dos problemas relacionam-se ao fato do isolamento, da fragmentação, da não relação do que se aprende em relação ao uso, ao direcionamento ao resultado final e à visão do texto como algo pronto. Dessa forma, uma disciplina que tem por objetivo desenvolver a produção de textos precisa aliar a teoria à prática, oferecendo oportunidades para que os alunos construam e reconstruam conhecimentos por meio dos textos produzidos. Além disso, em se tratando de uma disciplina de um curso de formação de professores, é necessário que ao elaborar as tarefas tenhamos o intuito de relacioná-las à futura prática docente dos alunos além de ressaltarmos as possibilidades de interligações.

Isso nos leva a uma prática escrita que observa o processo de elaboração dos textos inseridos em um contexto de produção, para uma determinada audiência e cujos objetivos são claros. Nesse caminho, tarefas que permitam que os textos sejam escritos, revistos, reescritos, discutidos e rediscutidos são destacadas. Assim, os textos produzidos em um determinado momento, podem 
ser reescritos e reorganizados posteriormente. É também pertinente que esses futuros professores vivenciem a produção de textos evidenciando o processo, ou seja, considerando a existência de um produto final sem que ele esteja isolado e dissociado do processo que levou à sua construção.

No que se refere especificamente a produzir textos na escola, Passarelli (2012, p. 46) afirma:

A produção de textos na escola é uma atividade realizada como exercício para desenvolver a capacidade textual do sujeito. Por se tratar de um trabalho de reflexão individual e/ou coletiva que depende de uma série de habilidades, o papel da escola é criar situações interlocutivas propícias para que o estudante aprenda a escrever melhor seus textos.

Outro aspecto destacado por Passarelli (2012, p. 65) é a questão da escrita processual. Segundo ela, há "pouca atenção" a isso nos cursos de formação. Essa afirmação da autora é uma importante constatação e tratar a escrita como um processo é uma necessidade de um curso de produção textual.

Finalmente, Oliveira (2012) acredita que o processo de produção textual pode possibilitar o resgate de conhecimentos prévios, permite que ligações e religações com as situações de uso dos textos nos mais variados contextos de atuação dos alunos sejam estabelecidas, bem como as relações com as demais disciplinas do curso, se a considerarmos como uma disciplina parte de um conjunto compõe um curso de graduação, promovendo a religação dos saberes. A produção de textos poderia, também, criar espaço para que conceitos opostos pudessem dialogar, como proposto pelo princípio dialógico, pois são constituintes da mesma realidade e não podem ser excluídos. Além disso, as ligações das partes entre si e ao todo e esse movimento de ir e vir que se estabelece poderiam remeter aos princípios recursivo e hologramático.

Notamos, portanto, que Oliveira (2012) observa a disciplina presencial de ensino de língua materna no curso de licenciatura em Educação Física e as oportunidades que ela poderia oferecer à formação desses professores pelo viés da complexidade. 


\section{Compartilhando reflexões}

Partindo das experiências das duas professoras pesquisadoras no que se refere às suas pesquisas e suas experiências como docentes que trabalham com a prática escrita, é possível destacar como o olhar complexo pode promover ações diversificadas. D'Esposito (2012) toma a complexidade por base do desenho e da implementação do curso a distância de prática escrita em língua inglesa para professores do ensino médio da rede pública, sendo ela também a visão que a professora pesquisadora tem da prática escrita entendida como processo. Por sua vez, Oliveira (2012) observa a disciplina presencial de ensino de língua materna direcionada à produção textual em um curso de licenciatura em Educação Física e a formação desses futuros professores pelo viés da complexidade. Dessa forma, apresentamos neste artigo duas experiências de pesquisa e docência que trabalham sob a perspectiva da complexidade e com a prática escrita.

Tanto o curso a distância de prática escrita em língua inglesa como a disciplina de produção textual em língua materna buscavam o não isolamento ou fragmentação dos saberes, buscando estabelecer uma relação entre as aulas, o curso em questão, a prática escrita e a vida pessoal, acadêmica e profissional dos professores participantes, contando com as vozes, os conhecimentos e as experiências de todos os indivíduos envolvidos. Almejamos a articulação, o complexus proposto por Morin ([1999] 2006a, p. 89; [2008] 2010, p. 190), ou seja, "o que é tecido junto".

Para que isso seja possível, os cursos devem oferecer oportunidades para que os próprios textos se inter-relacionem, sejam reelaborados e que, para produzi-los, os alunos busquem ou recorram a seus conhecimentos e não apenas a modelos prontos, fixos e acabados. Almeja-se vivenciar a escrita como um processo de construção/desconstrução/reconstrução e autonegociação de significados, tendo acesso não apenas à teoria sobre produção de textos, mas também à prática. 
Assim, a produção de textos é entendida como uma experiência processual que permite aos professores participantes acessarem conhecimento prévio sobre a língua em questão bem como aqueles construídos ao longo da vida, de forma recursiva, hologramática e dialógica. É, portanto, um processo dinâmico, de avanço e retrocesso que promove infinitas relações e interações que permitem transformações e oportunidades de aprendizagem. Há a possibilidade de construção e reconstrução de conhecimentos sobre a língua, do assunto sendo tratado no texto, além do estabelecimento de relações não previstas. Dessa forma, os textos produzidos em língua materna ou estrangeira não têm um fim em si mesmos; ou seja, não são apenas o produto ou a finalidade do curso ou da disciplina, mas um aspecto relevante para a formação do indivíduo contemporâneo.

Ao compartilharmos nossa visão complexa de ensino e nossas experiências de pesquisa e docência, nosso objetivo é gerar reflexões acerca das contribuições da perspectiva da complexidade no desenvolvimento de pesquisas, no desenho e implementação de cursos presenciais e a distância e no trabalho desenvolvido na formação de professores, buscando um novo olhar para a educação e a construção de conhecimento que procura romper com o paradigma tradicional.

\section{Referências bibliográficas}

ANTUNES, I. Aula de Português: encontro \& interação. São Paulo: Parábola Editorial, 2003.

ASSMANN, H. Metáforas para reencontrar a educação. São Paulo: Unimep, 1998.

BEHRENS, M. A.; OLIARI, A. L. T. A evolução dos paradigmas na educação: do pensamento científico tradicional a complexidade. In: Diálogo Educacional, Curitiba, v.7, p. 53-66, 2007. 
CINTRA, A. M. M. Bases para uma proposta de ensino de Português Instrumental. In: MARQUESI, S. C. (org.). Português Instrumental: uma abordagem para o ensino de língua materna. São Paulo: EDUC, p. 17 - 23, 1996.

COX, B. Writing. In: S. BRINDLEY (ed.). Teaching English. The Open University Press, 1994.

D’ESPOSITO, M. E. W. Prática escrita em língua inglesa: um curso online para professores da rede pública estadual, sob a perspectiva da complexidade. Tese de Doutorado. Programa de Estudos Pós-Graduados em Linguística Aplicada e Estudos da Linguagem. Pontifícia Universidade Católica de São Paulo, São Paulo, 2012.

FIORIN, J. L. O ensino de português nos níveis fundamental e médio: problemas e desafios. In: L. Scholze; T. M. K. Rösing (orgs.). Teorias e práticas de letramento. Brasília: Instituto Nacional de Estudos e Pesquisas Educacionais Anísio Teixeira, p. 95-116, 2007.

FRIEDLANDER, A. Composing in English: effects of a first language on writing in English as a second language. In: B. KROLL (ed.). Second Language Writing. Research insights for the classroom. United Kingdom: Cambridge Applied Linguistics, 1996.p. 109-125.

GRABE, W; KAPLAN R. B. Theory \& Practice of Writing. England: Longman, 1996.

GRAEFF, T. F.; ONHATTE, F. O domínio do código escrito em redações de vestibular. In: Desenredo, Revista do Programa de Pós Graduação em Letras da Universidade de Passo Fundo, v. 2, p. 159-178, 2006.

KUHN, T. S. A estrutura das revoluções científicas. São Paulo: Perspectiva, [1962] 2009.

MARIOTTI, H. Pensamento complexo: suas implicações à liderança, a aprendizagem e ao desenvolvimento sustentável. São Paulo: Atlas, 2007.

MAYBIN, J. Teaching writing - process or genre? In: S. BRINDLEY (ed.). Teaching English. London: The Open University Press, 1996, p. 166-173.

MORAES, M. C. O paradigma educacional emergente. São Paulo: Papirus, 2006.

MORIN, E. Ciência com consciência. Rio de Janeiro: Bertrand Brasil, [1990] 2008.

A cabeça bem-feita: repensar a reforma, reformar o pensamento. Rio de Janeiro: Bertrand Brasil, [1999] 2006a. 
Cortez Editora, [1999] 2006b. [2005] 2006.

Introdução ao Pensamento Complexo. Porto Alegre: Editora Sulina,

Meu caminho. Entrevistas com Djéanne Kareh Tager. Rio de Janeiro: Bertrand Brasil, [2008] 2010.

OLIVEIRA, G. Uma caminhada pela vivência de graduandos em Educação Física na disciplina Produção Textual, pelo percurso da complexidade. Tese de Doutorado. Programa de Estudos Pós-Graduados em Linguística Aplicada e Estudos da Linguagem. Pontifícia Universidade Católica de São Paulo, São Paulo, 2012.

PASSARELLI, L. M. G. Ensino e Correção na produção de textos escolares. São Paulo: Cortez Editora, 2012.

PAVANELLO, V. L. A. B. O ensino de Língua Portuguesa no curso de Educação Física da UNIVILLE: uma abordagem instrumental. Dissertação de Mestrado em Ciências Humanas: Língua Portuguesa. Pontifícia Universidade Católica de São Paulo, São Paulo, 1995.

SÃO PAULO. Secretaria da Educação. Proposta Curricular do Estado de São Paulo: Inglês. SE/SEE, 2008.

SÃO PAULO. Secretaria da Educação. Caderno do professor: LEM- Inglês,

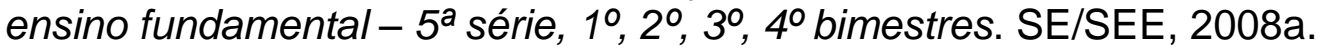

SÃO PAULO. Secretaria da Educação. Caderno do professor: LEM- Inglês,

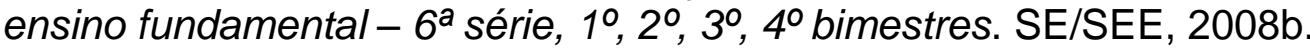

SÃO PAULO. Secretaria da Educação. Caderno do professor: LEM- Inglês,

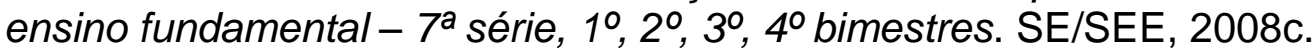

SÃO PAULO. Secretaria da Educação. Caderno do professor: LEM- Inglês,

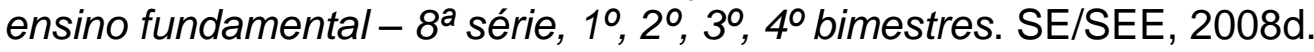

SÃO PAULO. Secretaria da Educação. Caderno do professor: LEM- Inglês,

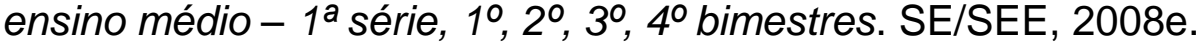

SÃO PAULO. Secretaria da Educação. Caderno do professor: LEM- Inglês, ensino médio - $2^{a}$ série, $1^{\circ}, 2^{\circ}$, $3^{\circ}$, 4ํo bimestres. SE/SEE, $2008 \mathrm{f}$.

SÃO PAULO. Secretaria da Educação. Caderno do professor: LEM- Inglês,

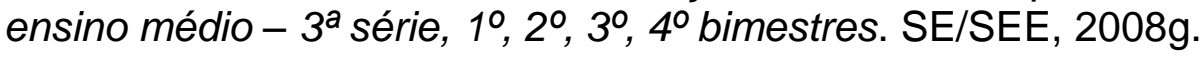


ZAMEL, V. Writing: The process of Discovering Meaning. In: M. H. LONG \& J. C. RICHARDS (ed.). Methodology in TESOL: a book of readings. Newbury House Publishers, 1987, p. 267-278.

Artigo recebido em: 30 de abril de 2013

Artigo aprovado em: 20 de maio de 2013

Sobre a autora Maria Eugenia Witzler D’Esposito:

Doutora em Linguística Aplicada e Estudos da Linguagem pela Pontifícia Universidade Católica de São Paulo (2012).

Sobre a autora Gisele de Oliveira:

Doutora em Linguística Aplicada e Estudos da Linguagem pela Pontifícia Universidade Católica de São Paulo (2012). 